undergoing multiple redo mitral valve surgery. A right thoracotomy requires minimal retraction and dissection of the heart and provides good exposure of the mitral valve. Cardiopulmonary bypass on ventricular fibrillation can decrease the manipulation of the aorta without aortic cannulation and cross-clamps. The disadvantage of this approach is the increased risk of cerebral vascular insufficiency. ${ }^{5}$ Femoral arterial cannulation can cause stroke if the aorta has atherosclerotic changes. When the femoral artery is unavailable, arterial cannulation can be achieved using the right subclavian artery. Because air embolism is also a cause of stroke, vent placement across the aortic root and carbon dioxide flooding of the thoracic cavity are recommended to remove air from the heart. The repeat leak incidence after surgical treatment of mitral PVL has been reported to be $22 \%{ }^{1}$ For PVL repair without repeat replacement, the leak size and location should be defined accurately by preoperative transesophageal echocardiography. In the present cases, we decided that their PVLs could be treated using this technique because of the small leak size and number. If the size is large or multiple leaks are present, repeat MVR might be adequate for PVL treatment. A durable repair technique is also necessary for PVL closure. We present a double-closure technique for mitral PVL repair with both pledgeted sutures and a pericardial patch that might provide greater durability. Even if the mitral annulus becomes detached from the sewing ring, the patch will prevent recurrence of the leak. This technique provides an easy approach to the mitral valve, with durable repair of the leak and is 1 of the feasible options for patients undergoing surgery for mitral PVL.

\section{References}

1. Genoni M, Franzen D, Vogt P, Seifert B, Jenni R, Künzli A, et al. Paravalvular leakage after mitral valve replacement: improved long-term survival with aggressive surgery? Eur J Cardiothorac Surg. 2000;17:14-9.

2. Mangi AA, Torchiana DF. A technique for repair of mitral paravalvular leak. J Thorac Cardiovasc Surg. 2004;128:771-2.

3. Al Halees Z. An additional maneuver to repair mitral paravalvular leak. Eur J Cardiothorac Surg. 2011;39:410-1.

4. Ryomoto M, Mitsuno M, Fukui S, Miyamoto Y. Repair of perivalvular leakage without re-replacement of prosthetic valves. Eur J Cardiothorac Surg. 2011;40:525-6.

5. Svensson LG, Gillinov AM, Blackstone EH, Houghtaling PL, Kim K-H, Pettersson GB, et al. Does right thoracotomy increase the risk of mitral valve reoperation? J Thorac Cardiovasc Surg. 2007;134:677-82.

\title{
Transaortic balloon-expandable aortic valve implantation
}

\author{
Gino Gerosa, MD, ${ }^{\mathrm{a}}$ Assunta Fabozzo, MD, ${ }^{\mathrm{a}}$ Roberto Bianco, MD, ${ }^{\mathrm{a}}$ Giuseppe Tarantini, MD, ${ }^{\mathrm{b}}$ and \\ Augusto D'Onofrio, MD, ${ }^{\mathrm{a}}$ Padova, Italy
}

In patients with severe symptomatic aortic valve stenosis who are inoperable or at high risk for surgical aortic valve replacement, transcatheter aortic valve implantation (TAVI) represents an alternative therapeutic strategy. ${ }^{1} \mathrm{Cur}-$ rently, there are 2 commercially available devices: the selfexpandable CoreValve revalving system (Medtronic Inc, Minneapolis, Minn) and the balloon-expandable Sapien XT valve (Edwards Lifesciences, Irvine, Calif). For the latter, a transapical approach is the first choice in case of unavailable femoral access. However, in patients with severe left ventricular (LV) dysfunction, a surgical approach of the apex can potentially further worsen heart contractility, and the presence of an LV aneurysm with mural thrombi

\footnotetext{
From the Divisions of Cardiac Surgery, ${ }^{\mathrm{a}}$ and Cardiology, ${ }^{\mathrm{b}}$ University of Padova, Italy. Disclosures: Authors have nothing to disclose with regard to commercial support.

Received for publication June 17, 2011; revisions received Nov 17, 2011; accepted for publication Dec 6, 2011; available ahead of print Dec 19, 2011.

Address for reprints: Augusto D'Onofrio, MD, Division of Cardiac Surgery, University of Padova, via Giustiniani 2, CAP 35128, Padova, Italy (E-mail: adonofrio@ hotmail.it).

J Thorac Cardiovasc Surg 2012;143:1453-5

0022-5223/\$36.00

Copyright (C) 2012 by The American Association for Thoracic Surgery doi:10.1016/j.jtcvs.2011.12.005
}

contraindicates the procedure. Bleiziffer and colleagues ${ }^{2}$ reported that 1 year after transapical TAVI, a new apical hypo- or akinesia was present in up to $37 \%$ of patients, and that because of the apical scar, a significant reduction of the LV ejection fraction was found in $13 \%$ of patients. In these patients with "no access," a subclavian/axillary approach has been described, ${ }^{3}$ but it is not feasible in case a $29-\mathrm{mm}$ device is necessary or both subclavian arteries are heavily calcified or extremely tortuous. A transaortic implantation has been described using the CoreValve revalving system. ${ }^{4}$ We describe the technique for $29-\mathrm{mm} \mathrm{Sa}$ pien XT implantation via a transaortic access.

\section{CLINICAL SUMMARY}

A 70-year-old man with severe symptomatic aortic valve stenosis was admitted to the University of Padova for acute pulmonary edema. His aortic valve area was $0.74 \mathrm{~cm}^{2}$, peak and mean gradients were 38 and $21 \mathrm{~mm} \mathrm{Hg}$, respectively, LV ejection fraction was $22 \%$, and end-diastolic volume index was $118 \mathrm{~mL} / \mathrm{m}^{2}$. In this patient, the nature of LV dysfunction was related to the chronic occlusion of the right coronary artery with a consequent akinesia of the 

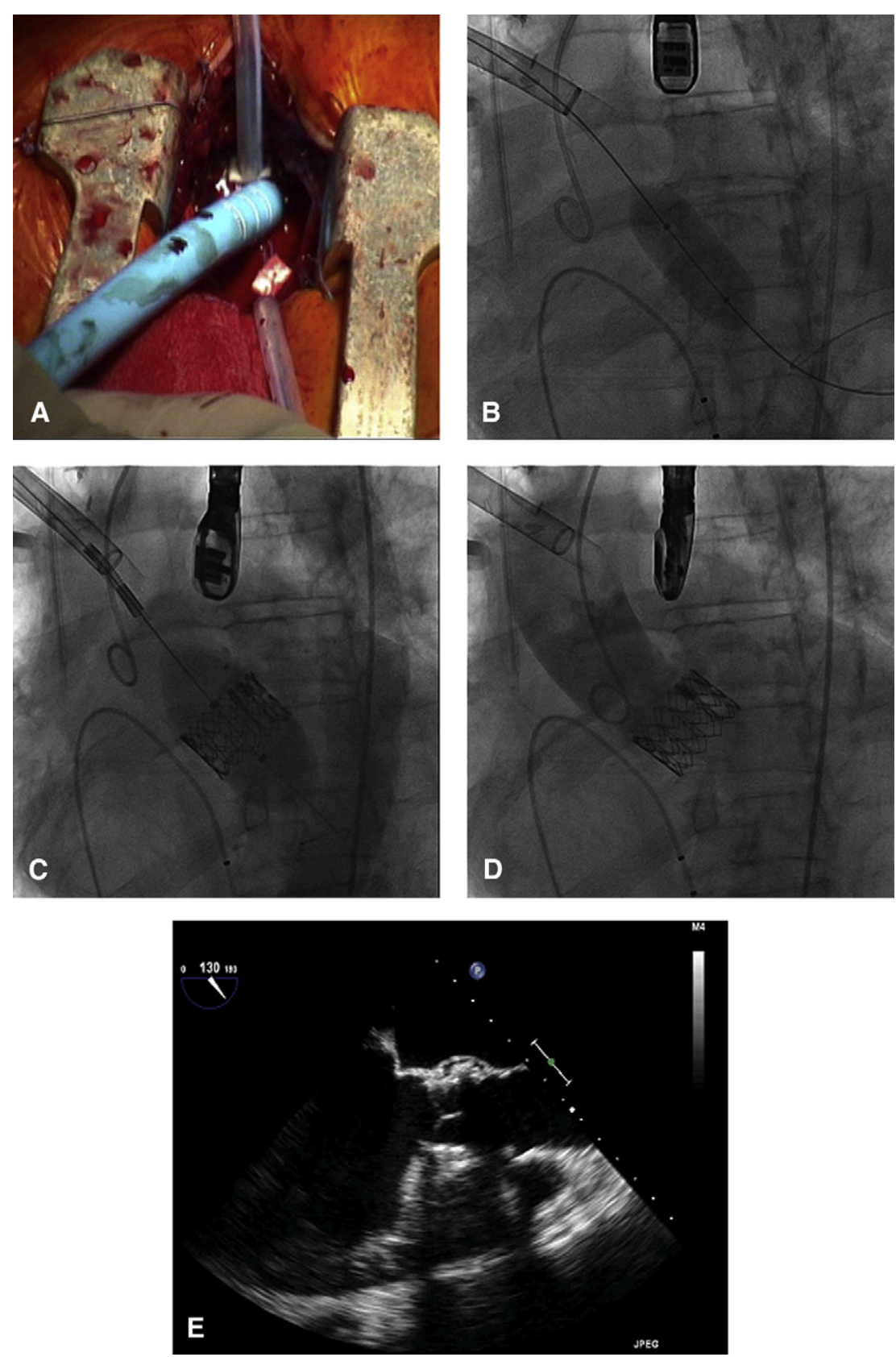

FIGURE 1. A, Intraoperative view of the Ascendra 2 sheath (Edwards Lifesciences, Irvine, Calif) introduced in the ascending aorta with 2 purse-string sutures. B, Transaortic balloon aortic valvuloplasty. C, Transaortic Sapien XT (Edwards Lifesciences) valve deployment. D, Absence of aortic regurgitation after balloon and guide wire retraction. E, Intraoperative transesophageal echocardiography shows correct positioning of the aortic valve prosthesis.

diaphragmatic ventricular wall and to the long-standing aortic valve pathology that led to a diffuse ventricular hypokinesia. The left coronary artery was normal, and there were no ventricular aneurysms. A dobutamine stress echocardiogram showed a slight improvement of the LV ejection fraction that reached $35 \%$ and an increase of peak transaortic gradient that reached $58 \mathrm{~mm} \mathrm{Hg}$.

The patient's comorbidities were severe chronic pulmonary obstructive disease requiring daily use of bronchodilators and steroids, diffuse arteriopathy, and a frail aspect.
Logistic European System for Cardiac Operative Risk Evaluation was $23 \%$ and Society of Thoracic Surgeons' mortality score was $11 \%$. The patient was scheduled for TAVI.

Preoperative angiography and computed tomography scan showed an aortic annulus diameter of $27 \mathrm{~mm}$, severe calcifications of the iliac-femoral vessels with a diameter less than $5.5 \mathrm{~mm}$, and small and tortuous subclavian/ axillary arteries. No calcifications of the ascending aorta were visible on computed tomography scan and aortic angiography. 
Aortic annulus diameter was confirmed by a transesophageal echocardiography. With these preoperative findings, we concluded that the only possible strategy was a $29-\mathrm{mm}$ Sapien XT implantation via a transaortic approach.

Under general anesthesia, a small anterior right thoracotomy was performed in the second intercostal space. After opening and suspending the pericardium, the ascending aorta was exposed. Two purse-string sutures with a diameter of $1.5 \mathrm{~cm}$ were made with a 3-0 braided stitch and Teflon pledget reinforcement.

Puncture of the aorta was performed in the middle of the purse-string sutures. Under fluoroscopic guidance, an angiographic guide wire was inserted retrogradely through the aortic valve in the left ventricle. Because the direction of the guide wire is not perpendicular to the plane of the aortic valve, particular attention should be given to avoid possible lesions to the aortic sinuses and aortic wall. A $6 \mathrm{~F}$ sheath was then placed on the guide wire through the aortic valve to exchange the guide wire with an extra-stiff one, following the already described transfemoral implantation technique. ${ }^{5}$ The 26F Ascendra 2 sheath (Edwards Lifesciences) was inserted in the ascending aorta (Figure 1, $A$ ) to perform subsequent balloon aortic valvuloplasty and valve deployment.

Aortic valvuloplasty was carried out with a $20-\mathrm{mm}$ balloon during 180 beats/min-induced ventricular tachycardia (Figure 1, B). A 29-mm Sapien XT valve was prepared on the Ascendra 2 delivery system with its inflow portion directed toward the tip of the catheter (ie, in the opposite position of a transapical procedure).

The prosthesis was then placed in the correct position (50\% below and $50 \%$ above the aortic annulus), and valve deployment was performed under induced ventricular tachycardia (Figure 1,C). Correct valve positioning and the absence of residual aortic valve regurgitation were confirmed by postprocedural aortic angiography (Figure $1, D$ ) and intraoperative transesophageal echocardiography (Figure 1,E).

The sheath was then removed, and the aortic purse-string sutures were tightened under induced ventricular tachycardia. The patient had an uneventful recovery and was discharged in good general and clinical conditions.

\section{CONCLUSIONS}

Transaortic implantation of the Sapien XT valve using the Ascendra 2 system via a small right anterior thoracotomy may represent a valid alternative for patients with severe aortic valve stenosis who are not eligible for surgical aortic valve replacement and who cannot undergo a retrograde transarterial or a transapical TAVI.

\section{References}

1. Leon MB, Smith CR, Mack M, Miller C, Moses JW, Svensson LG, et al. Transcatheter aortic valve implantation for aortic stenosis in patients who cannot undergo surgery. $N$ Engl J Med. 2010;363:1597-607.

2. Bleiziffer S, Piazza N, Mazzitelli D, Opitz A, Bauernschmitt R, Lange R. Apicalaccess-related complications associated with trans-catheter aortic valve implantation. Eur J Cardiothorac Surg. 2011;40:469-74.

3. De Robertis F, Asgar A, Davies S, Delahunty N, Kelleher A, Trimlett R, et al. The left axillary artery - a new approach for transcatheter aortic valve implantation. Eur J Cardiothorac Surg. 2009;36:807-12.

4. Latsios G, Gerkens U, Grube E. Transaortic transcatheter aortic valve implantation: a novel approach for the truly "no-access option" patients. Catheter Cardiovasc Interv. 2010;75:1129-36.

5. Cribier A, Litzler PY, Eltchaninoff H, Godin M, Tron C, Bauer F, Bessou JP. Technique of transcatheter aortic valve implantation with the Edwards-Sapien heart valve using the transfemoral approach. Herz. 2009;34:347-56.

\title{
A simplified technique for total anomalous pulmonary venous connection repair associated with functional single ventricle
}

\author{
Naritaka Kimura, MD, Ayumu Masuoka, MD, Toshiyuki Katogi, MD, and Takaaki Suzuki, MD, Saitama, \\ Japan
}

Surgical repair of total anomalous pulmonary venous connection (TAPVC) with single ventricle remains challenging because of the risk of late pulmonary venous obstruction. ${ }^{1,2}$

\footnotetext{
From the Department of Pediatric Cardiac Surgery, Saitama International Medical Center, Saitama Medical University, Saitama, Japan.

Disclosures: Authors have nothing to disclose with regard to commercial support.

Received for publication Sept 4, 2011; revisions received Nov 10, 2011; accepted for publication Dec 8, 2011; available ahead of print Jan 13, 2012.

Address for reprints: Naritaka Kimura, MD, 1397-1 Yamane, Hidaka-shi, Saitama 350-1298, Japan (E-mail: naritaku@mvf.biglobe.ne.jp).

J Thorac Cardiovasc Surg 2012;143:1455-7

$0022-5223 / \$ 36.00$

Copyright (c) 2012 by The American Association for Thoracic Surgery

doi:10.1016/j.jtcvs.2011.12.012
}

Since 2007, we have used the vertical vein to establish the continuity between the common atrium and the pulmonary vein without cutting into the pulmonary venous confluence. This report describes the outcome associated with this simplified technique for TAPVC repair.

\section{CLINICAL SUMMARY}

Six patients with single ventricle and TAPVC underwent TAPVC repair in the primary operation between October 2007 and September 2010. The institutional review board at Saitama International Medical Center, Saitama Medical University, Saitama, Japan, approved this retrospective 